\title{
Microscopic Endonasal Transsphenoidal Surgery in Patients with Small Nostril
}

\author{
Tsutomu Kato \\ Departments of Neurosurgery, Hakodate Central Hospital, Hakodate, Japan
}

\begin{abstract}
Recently, the endonasal transsphenoidal approach has been widely used as the standard technique for pituitary surgery instead of the sublabial approach. However, using this approach involves potential conflicts between surgical instruments when entering the nostril and while working inside even with an endoscope. In patients with small nostril, it requires an additional tension release incision to acquire sufficient working space, especially for the procedure with the speculum because the anterior nasal spine and the medial edge of the maxillary bone crest mainly limit the speculum opening. For children whose nostrils are less than $10 \mathrm{~mm}$ in diameter, an additional incision made across the base of the columella allows the speculum to spread to about 20 mm. For adults, such as women and Asians whose nostrils are around $10 \mathrm{~mm}$ in diameter, the disarticulation of the septal cartilage on the nasal crest of maxilla without columellar incision allows the speculum to spread to about $15 \mathrm{~mm}$. This report describes a simple technique with or without columellar incision using the microscopic endonasal transsphenoidal approach for patients with small nostril.
\end{abstract}

Key words: Columellar incision, endonasal approach, microscopic approach, small nostril, transsphenoidal surgery.

\section{Introduction}

The endonasal transsphenoidal approachhas been widely used for pituitary surgery, providing a less invasive approach, than the sublabial approach, which has several possible drawbacks including decreased surgical exposure due to overhanging lip [1], postoperative upper lip and incisor teethparesthesia, upper lip edema and pain, food retention in buccogingival fold, and gingival atrophy [2-4]. Although the endonasal route can minimize these postoperative oral complications [2, 5, 6], using this technique involves potential conflict between surgical instruments including an endoscope when entering the nostril and while working inside. Furthermore, in some cases of patients with small nostril, it is almost impossible to manipulatesurgical instruments including the endoscope through the one side of the nostrils.

The endonasal endoscopic transsphenoidal approach has been used recently for pituitary surgery,

Corresponding author: Tsutomu Kato, MD, research field: brain tumor. E-mail: tom-kato@qc4.so-net.ne.jp. but the author prefers a microscopic procedure to a purely endoscopic one because of its 3-dimensional view under direct vision, and restricts use of the endoscope to that of a support tool. The speculum is a requisite for the microscopic approach, but the anterior nasal spine and the medial edge of the maxillary bone crest mainly limit the speculum opening. In patients with small nostril, especially children, women, and Asians, an additional tension release incision is required to acquire sufficient working space and to prevent a skin laceration due to excessive speculum spreading.

There have been 2 main methods reported incision using the endonasal approach with an additional incision in patients with small nostril. One is an alar incision [3, 5-8] and the other is a columellar incision [1, 9-15].

The author has performed over 300 endonasal transsphenoidal operations using the unilateral-septal approach, and a modified technique for spreading the speculum in patients with small nostril had to be used in only 5 operations on 4 patients. Although this is not 
a common technique of the endonasal approach, it should be considered for patients with small nostril.

This report describes a simple technique, termed the “endonasal unilateral-septal midline transsphenoidal approach with or without columellar incision”, for patients with small nostril.

\section{Operative Technique}

The endonasal transsphenoidal approach, as originally described elsewhere [16], has been reported with several modifications [6, 8, 17-19].The nostril chosen for the approach is based mainly on tumor location, as defined by preoperative MR images obtained of the individual patient. For tumors projecting more to one side of the sella, the contralateral nostril is used, given that exposure across the midline to the contralateral sella is consistently wider than to the ipsilateral side because the middle turbinate in which the speculum is inserted commonly deflects the speculum to the opposite side [20]. In patients with relatively midline tumors, the right nostril is typically chosen, considering that the surgeon stands at the patient's right side.

In the author's standard endonasal unilateral-septal transsphenoidal approach, a vertical incision is made at the mucodermal junction of the nasal septum following the subperichondrial dissection, which extends to the anterior wall of the sphenoid sinus without disarticulation of the septal cartilage on the nasal crest of maxilla. The ipsilateral nasal mucosa is elevated from the nasal floor consecutively (Fig. 1A, 1D). The posterior part of the septal cartilage is disarticulated from the perpendicular plate of the ethmoid and vomer,

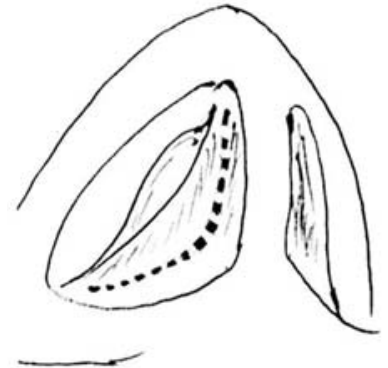

A

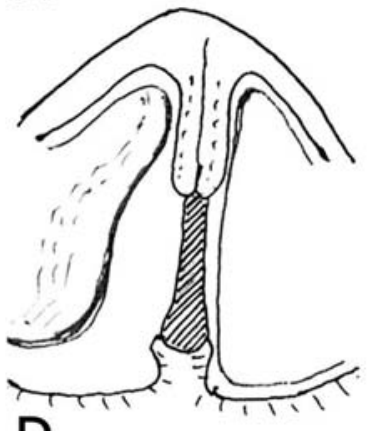

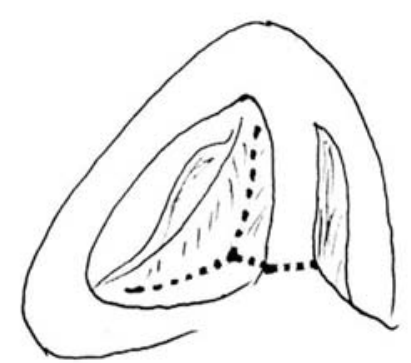

B

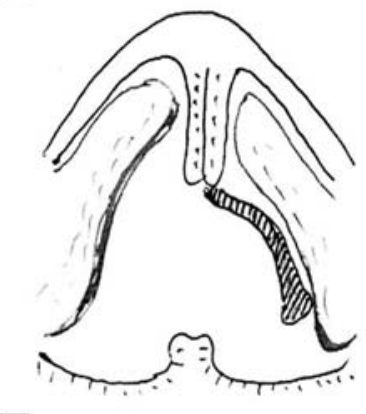

E

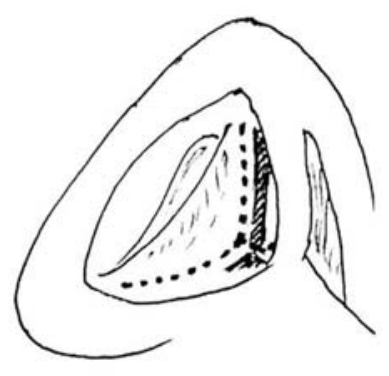

C

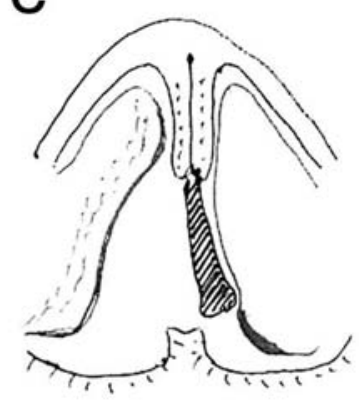

F

Fig. 1 The scheme of the incision of the author's various endonasal approaches.

Left: The standard endonasal unilateral-septal transsphenoidal approach. A vertical incision is made at the mucodermal junction of the nasal septum, which extends to the nasal floor (A: dotted line), and the nasal mucosa is dissected from the septal cartilage (D: shaded portion) and elevated from the ipsilateral nasal floor (D). Center: The endonasal unilateral-septal midline transsphenoidal approach with columellar incision. An additional incision is made across the base of the columella after the standard approach (B: dotted line). The septal cartilage (E: shaded portion) is disarticulated on the nasal crest of maxilla, and the nasal mucosa is elevated from both sides of the nasal floor with the septal cartilage and the incised columella (E). Right: The endonasal unilateral-septal midline transsphenoidal approach without columellar incision. The septal cartilage (C, F: shaded portion) is disarticulated on the nasal crest of maxilla without columellar incision after the standard approach (C: dotted line). The medial part of the contralateral nasal mucosa from the nasal floor is elevated with the septal cartilage (F: shaded portion). 
and the speculum is then inserted between the medial side of the mucoperichondrial flap and the contralateral side of the perpendicular plate of the ethmoid and vomer. At this stage, the anterior nasal spine and the medial edge of the maxillary bone crest as bony structures, limit the speculum opening when adopting this standard approach, and the speculum tends slightly toward the contralateral side with off-midline exposure of the keel of the sphenoid bone.

For children whose nostrils are less than $10 \mathrm{~mm}$ in diameter, an additional incision is made across the base of the columella after the standard endonasal unilateral-septal approach. Disarticulation of the septal cartilage on the nasal crest of maxilla extending to the junction with the perpendicular plate of the ethmoid bone, and elevation of the nasal mucosa from both sides of the nasal floor with the septal cartilage and the incised columella, which are pushed over to the contralateral side of the nostril (Fig. 1B, 1E), allow the ostium for the speculum to spread to about $20 \mathrm{~mm}$.

For adults whose nostrils are around $10 \mathrm{~mm}$ in diameter, the standard endonasal unilateral-septal approach following elevation of the medial part of the contralateral nasal mucosa from the nasal floor after disarticulation of the septal cartilage on the nasal crest of maxilla without columellar incision (Fig. 1C, 1F), allows the ostium for the speculum to spread about 15 mm with midline exposure of the anterior nasal spine.

After tumor removal, the nasal septal cartilage is repositioned to the midline, and care must be taken to place the cartilage on the anterior nasal spine. The incision in the mucodermal junction inside the nostril and the subcutaneous portion of the columella are approximated with 4-0 vicryl, and the columellar skin incision is approximated strictly with at least 4 stitches of 5-0 nylon for cosmetic purposes. Self-expanding synthetic sponges impregnated with antibiotic ointment are placed in both nostrils.

These modified endonasal approaches provide a midline trajectory to the sphenoid sinus and the sella turcica, which are termed the "endonasal unilateral-septal midline transsphenoidal approach with or without columellar incision”.

\section{Results}

These approaches were used twice in 1 patient who was a 9-year-old boy with craniopharingioma, and once in 3 patients who were 26, 59, and 62-year-old women with pituitary adenoma (Table 1). The 9-year-old boy's nostril was $9 \mathrm{~mm}$ in diameter (Fig. 2A) and a columellar incision allowed the ostium for the speculum to spreadto $20 \mathrm{~mm}$ (Fig. 2C). The tumor was totally removed gross through the speculum after acquiring sufficient working space. However, without postoperative radiation the tumor recurred 7 months later, and another gross total removal approached from the other side of the nostril with a columellar incision was performed. Postoperative radiotherapy following complete remission was added. The boy's columellar scar, 7 years later after the second incision, is cosmetically imperceptible and acceptable to the patient without any skin problems (Fig. 3).

Table 1 Summary of cases.

\begin{tabular}{|c|c|c|c|c|c|c|}
\hline Case & Age & Gender & Pathology & $\begin{array}{l}\text { Columellar } \\
\text { incision }\end{array}$ & $\begin{array}{l}\text { Nostril diameter } \\
\text { (approach side) }\end{array}$ & $\begin{array}{l}\text { Extent of ostium } \\
\text { using the author's } \\
\text { technique }\end{array}$ \\
\hline 1 & 9 & male & $\begin{array}{c}\text { Craniopharyngioma } \\
\text { Craniopharyngioma (recur.*) }\end{array}$ & $\begin{array}{l}+* * \\
+* *\end{array}$ & $\begin{array}{c}9 \mathrm{~mm} \text { (left) } \\
9 \mathrm{~mm} \text { (right) }\end{array}$ & $\begin{array}{l}20 \mathrm{~mm} \\
20 \mathrm{~mm}\end{array}$ \\
\hline 2 & 26 & female & Pituitary adenoma & $-* * *$ & $10 \mathrm{~mm}$ (right) & $15 \mathrm{~mm}$ \\
\hline 3 & 59 & female & Pituitary adenoma & $-* * *$ & $9 \mathrm{~mm}$ (right) & $15 \mathrm{~mm}$ \\
\hline 4 & 62 & female & Pituitary adenoma & $-* * *$ & 10 mm (right) & $14 \mathrm{~mm}$ \\
\hline
\end{tabular}

recur.*: recurrence;

**: endonasal unilateral-septal midline transsphenoidal approach with columellar incision;

***: endonasal unilateral-septal midline transsphenoidal approach without columellar incision. 


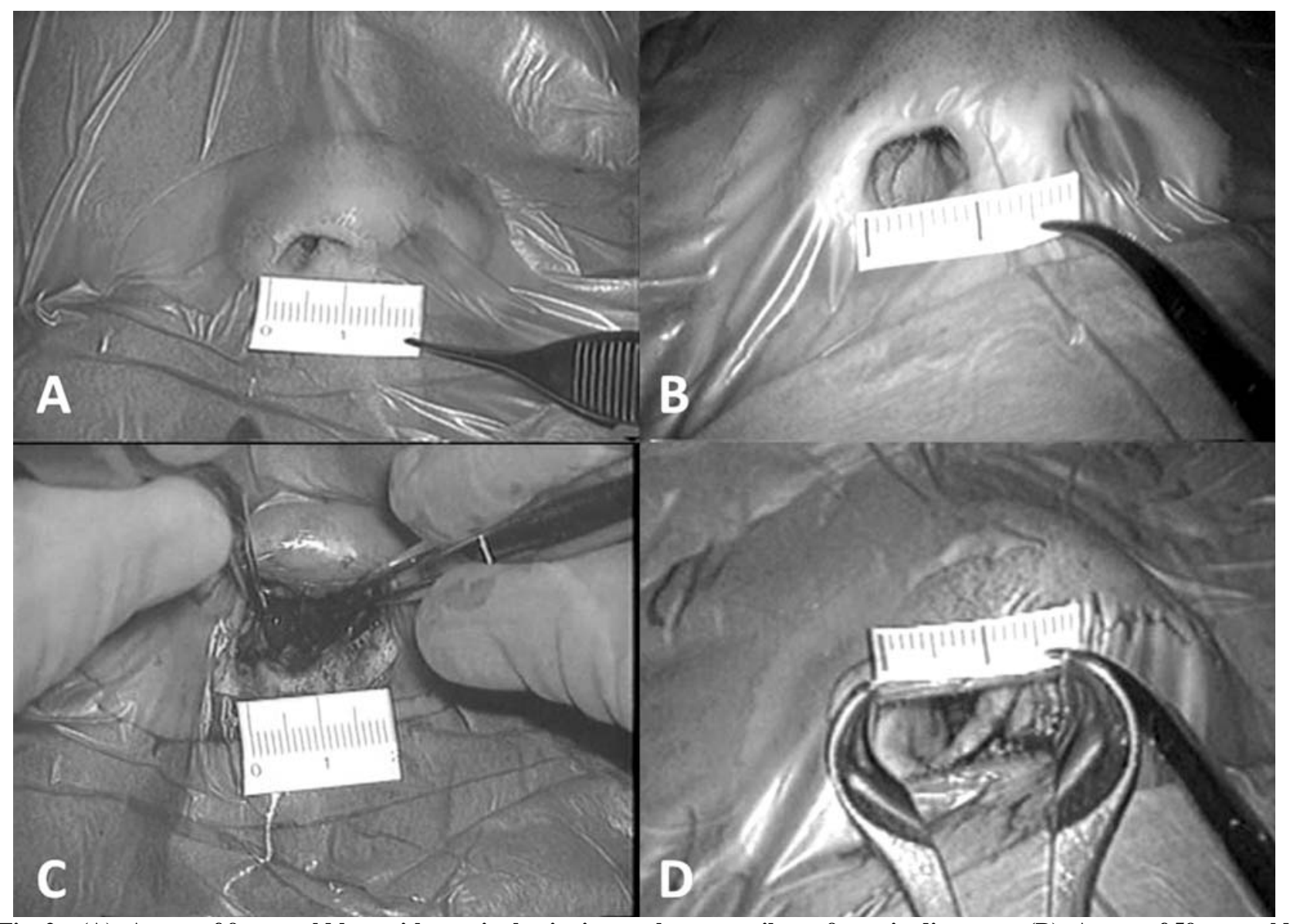

Fig. 2 (A): A case of 9-year-old boy with craniopharingioma whose nostril was 9 mm in diameter; (B): A case of 59-year-old woman with pituitary adenoma whose nostril was $9 \mathrm{~mm}$ in diameter; (C): A columellar incision allowed the ostium for the speculum to spread to $20 \mathrm{~mm}$ in 9-year-old boy; (D): This simple technique without columellar incision allowed the speculum to spread to $15 \mathrm{~mm}$ in 59-year-old woman.

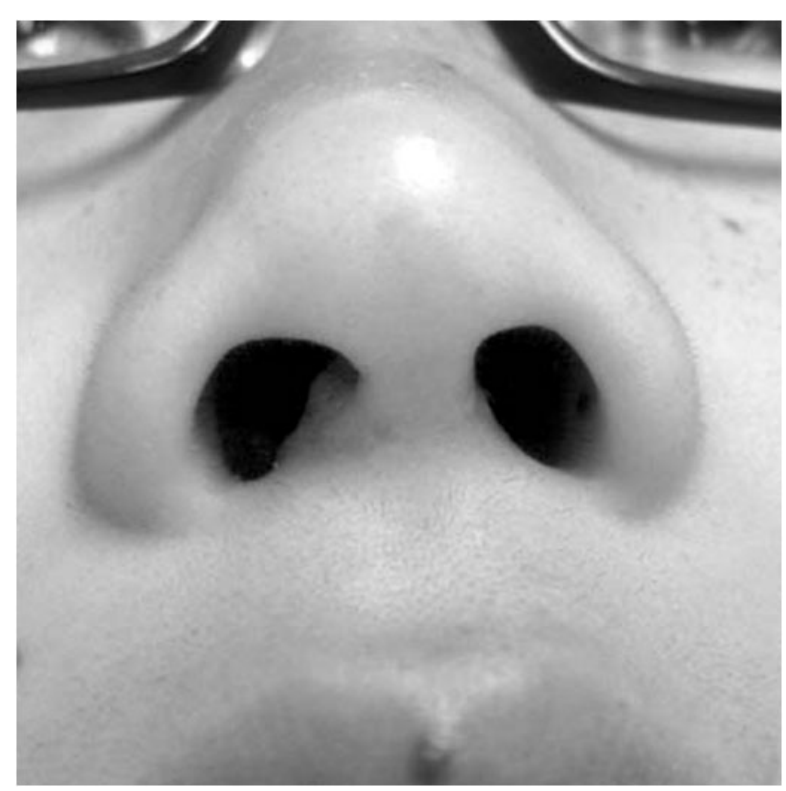

Fig. 3 The boy's columellar scar, 7 years later after the second incision, is cosmetically imperceptible without any skin problems.
This approach without columellar incision was applied to adult women, whose nostrils were 9 to 10 mm (mean: $9.7 \mathrm{~mm}$ ) in diameter (Fig. 2B), spreading the ostia to 14 to $15 \mathrm{~mm}$ (mean: $14.7 \mathrm{~mm}$ ) (Fig. 2D). During surgery, sufficient working space was acquired in each case for surgical manipulation through the speculum.

\section{Discussion}

Recently, the endoscopic transsphenoidal approach has been used more frequently for pituitary surgery than the microscopic approach. The endonasal route has also been widely used, providing a less invasive approach than the sublabial route, although slightly narrower and off-midline exposure is a potential problem. The author hasperformed over 500 
transsphenoidal operations, with approximately 300 cases recently approached through the endonasal route using a speculum under a microscope.

In patients with small nostril, especially children, women, and Asians, sufficient working space cannot be acquired in the speculum and excessive speculum spreading might cause a skin laceration. In these cases, the sublabial microscopic approach, a purely endonasal endoscopic approach without the speculum [18, 21] and using both nostrils [18], an approach using a novel instrument $[8,17,22,23]$ should be considered. The author has devised an endonasal microscopic approach with a simple technique that spreads the normal speculum to acquire sufficient working space and prevent skin laceration.

In the endonasal approach, the anterior nasal spine and the medial edge of the maxillary bone crest as bony structures, the nasal columella and the nasal ara as dermal structures, and the middle turbinate as a cartilaginous structure limit the speculum opening. So, an additional tension release incision is required in patients with small nostril. The endonasal approach is reported to apply 2 main methods employing an additional incision: a method with an alar incision [3, 5-8] and a method with a columellar incision [1, 9-15].

The alar incision (alotomy), which is made in the skin along the lateral nostril, can facilitate surgical exposure for the transnasal transsphenoidal approach [3, 5-8], which required alotomies in 5 to $33 \%$ in the literature $[4,5,7,8,24]$. The transnasal transsphenoidal approach is familiar to the otolaryngologist, by which surgical exposure can be obtained more rapidly with less surgical dissection and is based on a surgical procedure that preserves nasal form and function.

The columellar incision, using an external rhinoplasty approach, was suggested by Goodman WS et al. [11] in 1978 as an alternative to the sublabial transseptal approach, whose disadvantages such as postoperative lip and incisor numbness had been reported [1-3, 25]. Several modified methods with different forms of columellar incision include in this external rhinoplasty approach [10-12]. Freidberg SR et al. [10] described a V-shape incision made across the base of the columella after unilateral septal approach and the septal cartilage was either preserved or removed without mucosal elevation from the nasal floor. Kim SH et al. [12] reported the transcolumellar approach, by which a U-shape skin flap [1, 13] was elevated with the columella over the dome of the nose and the unilateral subperichondrial dissection at one side of the septal cartilage extended over the perpendicular plate of the ethmoid bone.

Schome SR et al. [25] investigated the advantages and disadvantages of 4 transseptal transsphenoidal approaches: sublabial, external rhinoplasy, alotomy, and transnasal. In this report, the advantages of the transseptal approach with alotomy were a faster technique with well-healed minimal external scar than sublabial or external rhinoplasty, and the ability to place theseptal incision either anteriorly or posteriorly at the ethmoid plate edge.In particular, the posterior septal incision was ideal for reoperation or previous septoplasty. However, disadvantages pointed out were the requirement of a relatively large nose and inability to place the retractor directly in midline. Another disadvantage reported was limited surgical exposure because the small size of the Killian incision limits the degree to which the speculum may be opened [3]. Dew LA et al. [7] reported that among 81 patients to whom the transnasal transsphenoidal approach was applied, 31 patients required alotomies to facilitate exposure in a small nasal cavity. Of these 31 cases, 1 patient noted a small scar at the site of an alar tear and 1 patient noted a small scar at the alotomy site, and there were 7 septal perforations.

In contrast, the following advantages of the external rhinoplasty approach were reported by Schome SR et al. [25]: (1) the retractor could be placed in midline; (2) the floor of the nose could be easily dissected because of direct vision; (3) preoperative nasal asymmetry 
could be corrected; and, (4) the small external incision was suitable for a small nose. The disadvantages were as follows: (1) $10 \%$ of columellar incisions were noticeable because of edema of upper columella or inaccurate reapproximation of skin incision; (2) a more meticulous closure was required than with the sublabial approach; (3) more postoperative care was required than with the sublabial approach; and, (4) there was potential for postoperative nasal deformity if healing was poor. Another report indicates advantages of the external rhinoplasty approach including wide exposure and shorter operative distance [1]. Although disadvantages such a columellar incision might result in a columellar deformity and scar as reported to occurin 2\% [13], postoperative nasal tip edema and woody feel of the nose were resolved after several months, usually within 3 months $[1,13]$. The reported experience of rhinoplastic surgeons using the external rhinoplasty approach has been that the columellar scar, when carefully closed, becomes inconspicuous with time [1, 13]. However, the columellar incision with prudent use should be considered in patients with keloid diathesis. Besides, the reported incident rate of septal perforation of $13 \%$ to $21 \%[13,15]$ was higher than when using the transnasal transsphenoidal approach with alotomy. Theoretically, this increased perforation rate might be related to the greater dissection and potential devascularization created by this exposure [7]. However, septal perforation is thought to be common with any technique using the transnasal approach and is caused by excessive spreading of the septal leaflets by the speculum [13].

Using the author's endonasal unilateral-septal midline transsphenoidal approach with columellar incision, postoperative nasal tip swelling and stiffness hardly occur because the columellar flap with the septal cartilage is pushed over to the contralateral side of the nostril compared tothe common external rhinoplasty approach, by which the columellar flap is raised onto the dome of the nose. Moreover, this technique makes it possible to approach the sellar floor solely through the bilateral submucosal nasal cavitiesas a surgical corridor with sufficient surgical space compared to the common external rhinoplasty approach, by which the nasal mucosa from one or both sides of the nasal floor is not elevated. The author's approach also eliminated the need for resection of the pyriform aperture to spread the surgical corridor.

The endonasal unilateral-septal midline transsphenoidal approach without columellar incision can be applied to adults with small nostrilusing the standard unilateral-septal approach with a simple technique that makes the septal cartilage disarticulate on the nasal crest of maxilla. Although this approach was performed in only 3 women with pituitary adenomas among over 300 endonasal transsphenoidal operations and is not a common technique of the endonasal approach, it should be considered forpatients with small nostril.

Arecent anatomical study reported that opening the speculum at the anterior wall of the sphenoid sinus beyond $2.5 \mathrm{~cm}$ carried some risk of damaging the optic nerves in the optic canals or orbit apex and neural structures in the wall of the sphenoid sinus, because the distance between both optic nerves at the anterior wall of the sphenoid sinus measures 2.71 to $3.09 \mathrm{~cm}$ (2.93 cm on average) [20]. $2.5 \mathrm{~cm}$ is a theoretical value and the ostium of the speculum is required to open more than $2.5 \mathrm{~cm}$ to gain the theoretical value. Because the anterior nasal spine and the medial edge of the maxillary bone crest as bony structures, the nasal columella and the nasal ara as dermal structures, and the middle turbinate as a cartilaginous structure limit the speculum opening with the endonasal transsphenoidal approach, the author's endonasal approach is reasonable for spreading the ostium of the speculum to prevent damage to neural structures.

\section{Conclusion}

This report describes a simple technique, termed the 
"endonasal unilateral-septal midline transsphenoidal approach with or without columellar incision”, which is a useful and applicable procedure using the speculum in patients with small nostril. Although this is not a common technique of the endonasal approach, it should be considered for patients with small nostril because of successful exposure is acquired through the speculum.

\section{References}

[1] P. J. Koltai, J. C. Goldstein, S. M. Parnes and J. C. Price, External rhinoplasty approach to transsphenoidal hypophysectomy, Arch Otolaryngol. 111 (1985) 456-458.

[2] K. Arita, T. Uozumi, T. Yano, K. Kurisu, T. Hirohata, T. Sadatomo, A. Takechi and K. Eguchi, Oral complication of sublabial transsphenoidal approach and advantage of endonasal transsphenoidal approach, No ShinkeiGeka 22 (1994) 119-124 (Jpn).

[3] P. D. Kenan, The rhinologist and management of pituitary disease, Laryngoscope 89 (Suppl 4) (1979) $1-26$.

[4] P. J. Sherwen, W. J. Patterson and D. E. Griesdale, Transseptal, transsphenoidal surgery: A subjective and objective analysis of results, J Otolaryngol. 15 (1983) 155-160.

[5] J. R. Dusick, F. Esposito, C. A. Mattozo, C. Chaloner, D. L. McArthur and D. F. Kelly, Endonasal transsphenoidal surgery: The patient's perspective survey results from 259 patients, Surg Neurol. 65 (2006) 332-342.

[6] G. Zada, D. F. Kelly, P. Cohan, C. Wang and R. Swerdloff, Endonasal transsphenoidal approach for pituitary adenomas and other sellar lesions: an assessment of efficacy, safety, and patient impressions, J Neurosurg. 98 (2003) 350-358.

[7] L. A. Dew, J. R. Haller and S. Major, Transnasal transsphenoidal hypophysectomy: Choice of approach for the otolaryngologist, Otolaryngol Head Neck Surg. 120 (1999) 824-827.

[8] N. Fatemi, J. R. Dusick, M. A. de Paiva Neto and D. F. Kelly, The endonasal microscopic approach for pituitary adenomas and other parasellar tumors: A 10-year experience, Neurosurgery 63 (Suppl 2) (2008) ONS 244-256.

[9] K. Das, W. Spencer, C. I. Nwagwu, S. Schaeffer, E. Wenk, M. H. Weiss and W. T. Couldwell, Approaches to the sellar and parasellar region: Anatomic comparison of endonasal-transsphenoidal, sublabial-transsphenoidal, and transethmoidal approaches, Neurol Res. 23 (2001) $51-54$.

[10] S. R. Freidberg, R. L. Hybels and P. Oliver, Intranasal approach to the sella turcica, Surg Neurol. 12 (1979) 145-146.

[11] W. S. Goodman and D. A. Charles, Technique of external rhinoplasty, J. Otolaryngol. 7 (1978) 13-17.

[12] S. H. Kim, J. H. Yoon, J. U. Choi, S. S. Chung and K. C. Lee, Transcolumellar approach in transsphenoidal pituitary surgery for patients with small nostril, Otolaryngol Head Neck Surg. 125 (2001) 609-612.

[13] P. J. Koltai, D. B. Goufman and S. M. Parnes, Transsphenoidal hypophysectomy through the external rhinoplasty approach, Otolaryngol Head Neck Surg. 111 (1994) 197-200.

[14] J. A. McCurdy, T. E. Van StantJr and D. W. S. Yim, Transseptal, transsphenoidal hypophysectomy via the external rhinoplasty approach, J Otolaryngol. 7 (1978) 29-31.

[15] S. M. Parnes and P. J. Koltai, External rhinoplasty approach to transsphenoidal hypophysectomy, Ear Nose Throat J. 70 (1991) 438-440.

[16] H. B. Griffith and R. Veerapen, A direct transnasal approach to the sphenoid sinus. Technical note, J Neurosurg. 66 (1987) 140-142.

[17] R. A. Chole, C. Lim, B. Dunham, M. R. Chicoine and R. G. Dacey Jr, A novel transnasal transsphenoidal speculum: a design for both microscopic and endoscopic transsphenoidal pituitary surgery, J. Neurosurg. 114 (2011) 1380-1385.

[18] H. D. Jho and R. L. Carrau, Endoscopic endonasal transsphenoidal surgery: Experience with 50 patients, J. Neurosurg. 87 (1997) 44-51.

[19] H. D. Jho and A. Alfieri, Endoscopic transsphenoidal pituitary surgery: Various surgical techniques and recommended steps for procedural transition, $\mathrm{Br} \mathrm{J}$ Neurosurg. 14 (2000) 432-440.

[20] A. S. Garcia and A. L. Rhoton Jr, Speculum opening in transsphenoidal surgery, Neurosurgery 59 (Suppl 1) (2006) ONS 35-40.

[21] N. Saeki, K. Horiguchi, H. Murai, Y. Hasegawa, T. Hanazawa and Y. Okamoto, Endoscopic endonasal pituitary and skull base surgery, Neuro Med Chir. (Tokyo) 50 (2010) 756-764.

[22] K. Arita, K. Kurisu, A. Tominaga, S. Ohba, F. Ikawa, K. Iida and H. Yoshida, Transsphenoidal "cross court" approach using a slightly modified speculum to reach pituitary adenomas with lateral growth, Acta Neurochir. (Wien) 142 (2000) 1055-1058.

[23] N. Fatemi, J. R. Dusick, D. Malkasian, J. Emerson, D. L. McArthur, W. Schad and D. F. Kelly, A short trapezoidal 
speculum for suprasellar and infrasellar exposure in endonasal transsphenoidal surgery, Neurosurgery 62 (Suppl 2) (2008) ONS 325-330.

[24] H. M. Tucker and J. F. Hahn, Transnasal, transseptal sphenoidal approach to hypophysectomy, Laryngoscope 92 (1982) 55-57.
[25] S. R. Schoem, A. Khan and W. Wilson, Minimizing upper lip and incisor teeth paresthesias in approaches to transsphenoidal surgery, Otolaryngol Head Neck Surg. 116 (1997) 656-666. 